\title{
ESTADO DE SITUACIÓN DEL OCIO Y EL TURISMO SOSTENIBLE EN COSTA RICA
}

\section{SITUATION OF LEISURE AND SUSTAINABLE TOURISM IN COSTA RICA}

Revista Trama

Volumen 10, número 1

Enero - Junio 2021

Páginas 84-131

ISSN: 1659-343X

https://revistas.tec.ac.cr/trama

Mildred Acuña Sossa ${ }^{1}$ / Dinorah Calvo Alvarado ${ }^{2} /$ Yorlenny Fontana Coto $^{3}$

Fecha de recepción: 6 de junio, 2020.

Fecha de aprobación: 24 de marzo, 2021.

Acuña, M., Calvo, D. y Fontana, Y. (2021). Estado de situación del ocio y el turismo sostenible en Costa Rica. Trama, Revista de ciencias sociales y humanidades, Volumen 10, (1), Enero-Junio, págs. 84-131.

DOI: https://doi.org/10.18845/tramarcsh.v10i1.5784

1. Doctoranda en Educación y Tecnologías de la Información y Comunicación. Encargada de la Cátedra de Emprendedurismo Turístico. Universidad Estatal a Distancia (UNED). San José, Costa Rica.

Correo electrónico: macunas@uned.ac.cr ORCID: https://orcid.org/0000-0001-9400-5002

2. Funcionaria del Instituto de Gestión de la Calidad Académica de la UNED.

Correo electrónico: dcalvo@uned.ac.cr ORCID: https://orcid.org/0000-0002-5201-6210

3. Docente de la Universidad Estatal a Distancia (UNED). San José, Costa Rica.

UNED.

Correo electrónico: yfontano@uned.ac.cr ORCID: https://orcid.org/0000-0003-4041-2862 


\section{RESUMEN}

El trabajo presenta un acercamiento sobre el estado de situación del ocio y el turismo sostenible en Costa Rica, a partir de una serie de categorías de análisis tales como: sitios históricos y patrimoniales, actividades culturales programadas, espacios acuáticos, sitios de atracción cultural, sitios de atracción natural, servicios turísticos o actividades de entretenimiento, recreación y esparcimiento, actividades de aventura, sitios de educación natural y cultural y rescate de animales silvestres. El propósito es disponer de un estado de situación que oriente el desarrollo de investigaciones y propicie gestiones oportunas en aspectos diversos como política pública, planes locales o emprendimientos afines a la búsqueda de reducir la brecha que eventualmente se observa en el cumplimiento del derecho universal al ocio, la recreación y al turismo. El marco teórico orienta hacia la reflexión, sobre la actividad turística, la sostenibilidad, el turismo social, los destinos y lo que implica esta actividad económica en el desarrollo económico local. La metodología utilizada se centró en el análisis bibliográfico y en trabajo de campo, el cual permitió un acercamiento particular al objeto de estudio. En la conclusión, se destaca que el turismo supone acceso a gran cantidad de personas, quienes en principio deben tener derecho al ocio, por lo tanto, es una actividad para el disfrute de las personas de diferentes extractos sociales. Sin embargo, la accesibilidad a los diferentes sitios se da en función de una marcada diferencia del poder adquisitivo de las personas.

Palabras clave: Turismo, ocio, sostenibilidad, accesibilidad, destino turístico, desarrollo local.

\section{ABSTRACT}

The work presents an approach on the state of the leisure and sustainable tourism situation in Costa Rica, based on a series of category analyses such as: historic and heritage sites, programmed cultural activities, aquatic spaces, sites of cultural attraction, sites of natural attraction, tourist services or entertainment, recreation and leisure activities, adventure activities, natural and cultural education sites and rescue of wild animals. The purpose is to have a state of the situations affairs that guides the development of investigations and encourages timely management in various aspects such as: public policy, local plans or undertakings related to the search to reduce the gap that is eventually observed in the fulfillment of the universal right to leisure, recreation and tourism. The theoretical framework orients towards reflection sustainable tourism activity on, social tourism, destinations and what this economic activity implies in local economic development. The methodology used focused on bibliographic analysis and field work, which allowed a particular approach to the object of study. In the conclusion, it is highlighted that tourism implies access to a large number of people, who in principle should have the right to leisure, therefore, it is an activity for which people must be entitled to leisure of different social backgrounds. However, the accessibility to the different sites depends on a marked difference in the purchasing power of the people.

Key words: Tourism, leisure, sustainability, accessibility, tourist destination, local development. 


\section{INTRODUCCIÓN}

La actividad turística, ha cumplido un papel importante en la economía costarricense, razón por la cual, es de interés conocer el estado de situación del Ocio y Turismo Sostenible en el país, con el propósito de identificar vacíos para dar orientaciones o posibles líneas de trabajo para los destinos turísticos, las empresas y las instancias que tienen relación directa e indirecta con la actividad turística. El propósito final es que en el corto y mediano plazo se pueda cumplir con el principio de acceso universal al turismo.

Para conocer la situación del Ocio y Turismo Sostenible, se visitaron 67 sitios de las siete provincias del país. Por lo tanto, se aborda gran parte del territorio nacional, en algunos casos sitios con mayor concentración de actividades turísticas, en algunos otros, se visualiza la presión paulatina por el uso de los espacios de ocio y recreación.

En el marco del ocio y turismo sostenible, es de interés conocer las condiciones de accesibilidad, recreación, inclusión y derecho al turismo, las cuales tienen una relación directa con el turismo social. Por lo que resalta el interés en fomentar la discusión sobre estos temas para que haya un disfrute y aprovechamiento más amplio y equitativo de la población costarricense en esta actividad económica.

El sector turismo, debe tener una posición proactiva y de liderazgo sobre ésta temática, lo que conlleva a establecer diálogo entre los diferentes actores involucrados, como lo son, el Instituto Costarricense de Turismo, ente rector de la actividad, municipalidades, organizaciones locales, empresas turísticas y gestores del turismo.

Las líneas de trabajo son:

- Disponer de un estado de situación sobre el tema de Ocio y Desarrollo como derecho humano.

- Disponer de un marco conceptual y práctico que oriente el desarrollo de acciones futuras, en procura de una acción social orientada a la promoción de un derecho de todos al turismo, la recreación y el ocio.

- Disponer de un estado de situación que oriente el desarrollo gestiones oportunas en aspectos diversos como política pública, planes locales o emprendimientos, afines a la búsqueda de reducir la brecha que eventualmente se observa en el cumplimiento del derecho universal al ocio, la recreación y al turismo. 


\section{CONTEXTO}

Se hace una aproximación a algunos lineamientos teóricos y conceptuales, los cuales pretenden ser una herramienta para analizar los aspectos más relevantes sobre el ocio y el turismo sostenible en el país.

\section{a. El turismo como actividad dinamizadora de la economía}

Para referir el concepto de turismo como la gran sombrilla que enmarca la investigación desarrollada sobre Ocio y Turismo Sostenible en Costa Rica, se presenta la definición que ofrece la Organización Mundial de Turismo (OMT) como ente rector de esta actividad económica. Precisa lo siguiente:

El turismo es un fenómeno social, cultural y económico que supone el desplazamiento de personas a países o lugares fuera de su entorno habitual por motivos personales, profesionales o de negocios. Esas personas se denominan viajeros (que pueden ser o bien turistas o excursionistas; residentes o no residentes) y el turismo abarca sus actividades, algunas de las cuales suponen un gasto turístico. (OMT, 2008, p.1).

Basándose en esta definición, se vislumbra que el turismo tiene una concepción social, que busca atender y satisfacer necesidades de los viajeros, al involucrarse en la idiosincrasia, tradiciones y costumbres de las personas según los sitios turísticos visitados. Además de económica, ya que puede producir ingresos al país o región receptora acorde al flujo de visitación. Sin duda alguna, el turismo es una de las actividades más abarcadoras.

Aunque el ocio no conlleva necesariamente el desarrollo de una actividad turística, pues depende de su origen y elementos que integran su motivación, sí hay un tipo de ocio, el recuperativo -basado en las cuatro teorías de ocio de John Kelly-, que "cumple una misión de compensación ante las tareas de la vida cotidiana. El objetivo es la relajación y el descanso" (Águila, 2007, p. 87).

Como fenómeno social y apuntalando los motivos personales de desplazamiento que rescata la OMT en su concepción, uno de los aspectos que impulsan la visitación es justamente este tipo de ocio, el cual tiene un enfoque de recreación y turismo sostenible.

Ahora bien, al englobar el ocio desde la necesidad de relajación y descanso, el mismo tiene una perspectiva de derecho humano. La Organización de las Naciones Unidas (ONU) refiere en la declaración de 
derechos humanos en el artículo 2 que "Toda persona tiene los derechos y libertades (...), sin distinción alguna de raza, color, sexo, idioma, religión, opinión política o de cualquier otra índole, origen nacional o social, posición económica, nacimiento o cualquier otra condición" (ONU,1948).

Se visualiza como una necesidad intrínseca del ser humano, que todas las personas necesitan descanso y recreación, existen deberes, obligaciones y tareas que cumplir ligadas algún trabajo, por ello debe existir una contraparte, en una relación de peso y contrapeso.

Sin embargo, el turismo como derecho humano es motivo de muchos debates y análisis, habiendo dos posiciones antagónicas. Autores como Breakey y Breakey (2013) lo estiman como Derecho Humano lo que es amparado por la OMT como lo evidencia en su misión- basados en la Declaración Universal de los Derechos Humanos, en el artículo 13, que refiere el derecho a la libre movilidad y el artículo 24 , que lo señala como derecho al descanso y a vacaciones pagadas (ONU, 1948).

Con otra perspectiva se encuentra autores como McCabe y Diekmann (2015) quienes estiman que se debe hablar de derecho social y no de derecho humano, llegando a la conclusión de que para que sea posible bajo esta figura es necesario destinar parte de los presupuestos públicos para garantizarlo. Para Higgins Desbiolles (2006 y 2011), al tratarse de un derecho debe estar desmaterializado, en concreto ser un bien público y no una mercancía, asegurando que mientras estas condiciones no se cumplan no puede ser un derecho universal (como se citó en Gascón, 2016. p. 55).

Derecho humano o social, es la disyuntiva que se expone, pero no hay duda que es una necesidad del ser humano y como tal ha sido dispuesto dentro del ámbito del turismo social, definido como el "Conjunto de actividades que genera una demanda turística caracterizada por sus escasos recursos económicos, de manera que el acceso al ocio turístico puede producirse solo mediante la intervención de unos agentes operadores que actúan tratando de mantener el beneficio colectivo" (Muñiz, 2001, p.43).

La OMT quizá es más específica en puntualizar la intervención de autoridades públicas como esos agentes operadores que buscan mantener el beneficio de la colectividad, señalando: 
Con el apoyo de las autoridades públicas, se desarrollará el turismo social, en particular el turismo asociativo, que permite el acceso de la mayoría de los ciudadanos al ocio, a los viajes y a las vacaciones. Se fomentará y se facilitará el turismo de las familias, de los jóvenes $y$ de los estudiantes, de las personas mayores y de las que padecen discapacidades tal y como lo establece el Código Ético Mundial para el Turismo (OMT, 1999, p. 8).

El surgimiento del turismo social tuvo como objetivo según se constata del párrafo anterior, el poner al alcance de las clases más desfavorecidas a nivel de recursos económicos, el acceso al ocio turístico, de modo que el derecho a este disfrute de experiencias y emociones, se ha conceptualizado la experiencia turística como "un conjunto de impresiones físicas, emocionales, sensoriales, espirituales y/o intelectuales que son percibidas de manera diferente por los turistas, desde el mismo momento en que planifican su viaje, lo disfrutan en el destino elegido e incluso cuando vuelven a su lugar de origen y recuerdan su viaje" (Fernández y Villarán, 2017, p.21).

El turismo social además presenta la particularidad como lo señala el Código Ético Mundial para el Turismo (1999), de integrar familias, jóvenes, personas mayores, sin distinción y con ello integra los viajes intergeneracionales, que no son más que familias -abuelos, padres e hijos- que deciden emprender un viaje juntos por diversos motivos, en estos tipos de viajes hay un enfoque especial a personas adultas mayores, quienes cuentan con la posibilidad de viajar en cualquier momento del año.

El turismo intergeneracional ha buscado diversificar la oferta turística, no ser un proyecto aislado, sino un producto turístico real y sostenible. Recordando que la sostenibilidad es y ha sido protagonista en el desarrollo de la actividad turística. Al respecto el Instituto Costarricense de Turismo (ICT) propone que:

El desarrollo turístico sostenible debe verse como la interacción balanceada entre el uso apropiado de nuestros recursos naturales y culturales, el mejoramiento de la calidad de vida de las comunidades locales, y el éxito económico de la actividad; además tiene que contribuir al desarrollo nacional. Sostenibilidad turística no solo es la respuesta a la demanda, sino es una condición indispensable para competir con éxito ahora y en el futuro (ICT, 1997). 
Uno de los pilares de la sostenibilidad turística, como lo rescata la conceptualización propuesta por el ICT, tiene ligamen con el éxito económico, por ser dinamizadora de la economía.

El turista es un gran consumidor de bienes y servicios, su presencia dinamiza diversos sectores de la economía. Los gastos de los visitantes se convierten en ingresos que permiten la generación de empleo (directo e indirecto), mayor inversión, divisas, encadenamientos productivos con otros sectores, ingresos fiscales; que bien administrados pueden impulsar el desarrollo y bienestar económico y social. Al respecto la OMT señala:

Durante décadas, el turismo ha experimentado un continuo crecimiento y una profunda diversificación, hasta convertirse en uno de los sectores económicos que crecen con mayor rapidez en el mundo. El turismo mundial guarda una estrecha relación con el desarrollo y se inscriben en él un número creciente de nuevos destinos. Esta dinámica ha convertido al turismo en un motor clave del progreso socioeconómico (OMT, 2018)

El impacto económico de la actividad turística ha superado o inclusive igualado exportaciones petroleras, de productos alimentarios o automóviles, según lo señala la OMT (2018):

El turismo se ha convertido en uno de los principales actores del comercio internacional, y representa al mismo tiempo una de las principales fuentes de ingresos de numerosos países en desarrollo. Este crecimiento va de la mano del aumento de la diversificación y de la competencia entre los destinos.

\section{b. Las diferentes aristas de los Destinos Turísticos}

Los destinos turísticos son áreas que presentan características reconocidas por los potenciales turísticos, quienes se ven atraídos por estos sitios y sus atracciones, independientes de otras zonas. Además, estos destinos engloban una serie de recursos turísticos e infraestructuras, formando un sistema que integra los servicios y productos que el turista percibe en sus vacaciones como parte de la experiencia global (Bigne, Font y Andreu, 2000, pp.30-31).

Para Quesada (2014) los destinos turísticas, son sitios que cuentan con atractivos turísticos, tales como lugares, objetos o acontecimientos de interés turístico, que nos motivan a las personas a trasladarse para apreciarlos o experimentarlos. Los atractivos turísticos se pueden 
clasificar de diferentes maneras, dependiendo de la interpretación que se le dé, según su origen naturales o creados por el hombre o según sus características naturales o culturales en Tangibles (perceptibles y espacialmente ubicados) e Intangibles (eventos, acontecimientos temporales o finitos). Tal y como se observa en la siguiente ilustración, clases de atractivos:

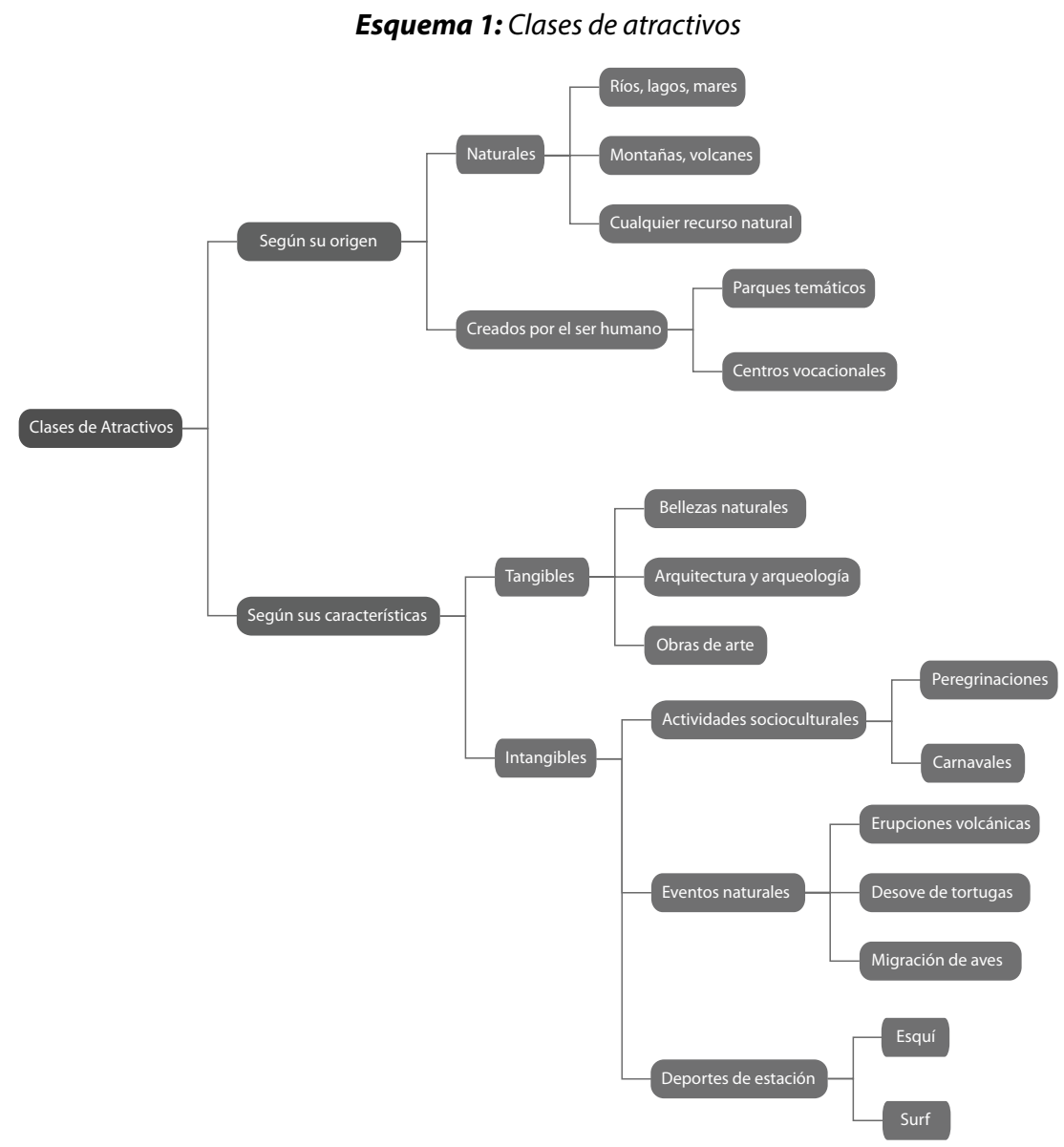

Fuente: elaborado a partir de Quesada (2014, p. 171). 
Tal y como lo indica Almirón et al. (2006) y Noyola y Campón (2016) "Los atractivos turísticos constituyen un elemento crítico en la construcción de un destino, que se produce a través de la puesta en valor para resaltar las características del sitio" (p.65). Además, un reto a la hora de gestionar un destino turístico es establecer el elemento diferenciador, de autenticidad, que permita al turista por un lado seleccionar este sitio para vacacionary por otro, que en el sitio logre sentir y vivir una experiencia única, difícil de ser igualada por otro destino (Noyola y Campón, 2016; Vilar y Vidal, 2010). Es importante indicar que la percepción de autenticidad es individual, es la sensación que una persona experimenta, pueden ser visual, narrativa, emocional, ambiental e inclusive, escenificada o superficial. "La autenticidad no es creada para atraer, es utilizada para que realmente el turista vea al destino y sus recursos patrimoniales tales como son y los distinga de los demás, posibilitando a la oferta turística ventajas competitivas" (Vilar y Vidal, 2010, p. 51).

En un destino turístico consolidado la infraestructura turística está presente y se conoce como el conjunto de elementos o servicios que se consideran necesarios para la creación y funcionamiento de la actividad turística. Tales como: 1. Planta turística, estructura productiva, conforma los servicios turísticos directos como hoteles, restaurantes, transportación, agencias de viajes y la superestructura (organización del quehacer turístico). Cabe indicar que el producto turístico de la planta turística se desarrolla de acuerdo a las características del espacio físico y considerando los deseos de los usuarios (Quesada, 2014, pp. 180-181).

En este sentido, para lograr una atención de calidad en los servicios y productos que se le brindan al turismo hay que considerar la capacidad de carga del destino turístico, no sólo cuántos turistas pueden recibir de acuerdo a la capacidad de la plata turística sino, cuál el número adecuado que puede abarcar un determinado espacio, recurso o destino turístico, que pueda preservar el entorno ambiental y la experiencia del turista; cumplimento de esta manera sus necesidades y expectativas. Para brindar servicios y productos de calidad, se debe considerar varias cualidades de elementos que lo conforman y la relación entre ellos (Gándara, 2004). Sin duda alguna, la calidad del servicio o producto va influir en la satisfacción del cliente y en la experiencia que éste haya tenido en relación a la ubicación, limpieza, comodidad, transporte, seguridad, estado de las vías e instalaciones, señalización, cantidad y tipo de actividades recreativas, alimentación, trato recibido, entre otros. 
Los servicios y productos turísticos están creados para satisfacer las necesidades y deseos de sus clientes. Para ello, las empresas oferentes establecen el precio, los medios de distribución y el mercado meta a quien va dirigido. A nivel turístico, se pueden ofrecer productos tangibles visibles a la hora de comprar u otros intangibles como las actividades a experimentar. Además, dependiendo del tamaño de la empresa que brinda el servicio o producto y los recursos así de variada serán las estrategias de mercadeo y comercialización del producto, que su fin principal será motivar el interés del comprador a través de diferentes medios de comunicación seleccionados para llegar al cliente (Socatelli, 2015). Actualmente, se utiliza fuertemente las tecnologías de información y comunicación para llegar a los clientes de forma más oportuna. Con el internet se buscan lugares, se ven los precios, se conoce la disponibilidad, se reserva y se compran los servicios.

A través del turismo las personas se divierten, se entretienen; esta recreación es considerada como una actividad para el esparcimiento físico y mental en el tiempo libre. Lo que implica divertirse y entretenerse en lugares públicos o privados. Algunas de estas opciones están ligadas a establecimientos de hospedaje como hoteles $u$ otros a sitios como parques públicos o centros de recreo privados o gremiales. Para visitar los sitios privados hay que considerar la capacidad de espacio, distancia, el nivel adquisitivo del cliente y el tamaño de la familia.

\section{c. Una aproximación teórica al concepto de Desarrollo Económico Local}

Boisier (2005) define desarrollo económico local como:

Un proceso de crecimiento económico y de cambio estructural que conduce a una mejora en el nivel de vida de la población local, en el que se pueden identificar tres dimensiones: una económica, en la que los empresarios locales usan su capacidad para organizar los factores productivos locales con niveles de productividad suficientes para ser competitivos en el mercado; otra sociocultural, en la que los valores y las instituciones sirven de base al proceso de desarrollo; $y$, finalmente, una dimensión política - administrativa, donde las políticas territoriales permiten crear un entorno económico local favorable, protegiendo de interferencias externas e impulsando el desarrollo local. 
En este sentido, el desarrollo está localizado en las características económicas, sociales, políticas y culturales de un lugar específico. Ello implica que se provoque un proceso endógeno. Para que ello se dé, se deben implementar una serie de estrategias, que deben considerar las particularidades de cada lugar para que esto sea efectivo.

Por otro lado, Alburquerque (2001) resalta otros aspectos que caracterizan lo Económico Local, como:

Es la movilización de actores sociales territoriales, el abandono de la lógica del subsidio por la participación y la articulación de las actuaciones en el ámbito local con reformas estructurales, además de que esta visión del desarrollo pone énfasis en los procesos, más que en los resultados.

El desarrollo económico local pone en valor las potencialidades locales, promoviendo las dinámicas económicas y la mejora de vida de la población, lo que permite insertarse en los mercados, siempre y cuando se tengan alternativas económicas, un marco político favorable y capacidad de negociación de la población local.

En las localidades, es indispensable potenciar el recurso humano, a través de sus capacidades técnicas y personales, reactivando las pequeñas empresas, adaptándose a nuevas tecnologías y procesos educativos que provoquen una visión de desarrollo empresarial para el mediano y largo plazo.

\section{d. Tendencias turísticas}

La aplicación del concepto de sostenibilidad a la industria turística sigue siendo una de las grandes preocupaciones en el ámbito mundial. Analistas y estudiosos mencionan el fenómeno relacional en el que se encuentran desde hace muchos años. Entendiendo que el nexo de unión, la argamasa que los une, es otro concepto que engloba y transgrede el mismo concepto de turismo. Se trata del concepto de ocio, del que ya se entiende como una experiencia subjetiva, desvinculada del concepto tiempo y del concepto actividad. 
Enmarcados en esta perspectiva de ocio, otros ámbitos se conectan e interactúan entre ellos. Así, las interrelaciones que se dan entre cultura, economía, población, infraestructura, estilos de vida y de consumo o legislaciones específicas, según, por ejemplo, Rodríguez Antón y Alonso (2009), relacionan entre sí para abrir nuevos horizontes a valores y productos que hoy se consideran como nuevas tendencias tanto en el ocio como en el turismo.

Estas nuevas tendencias juegan en principio con las tres columnas básicas de la sostenibilidad (económica, social y lo ambiental), pero no se quedan ahí en ellas, sino que se abren a matices mucho más específicos y concretos que facilitan la creación y posterior gestión de las nuevas ofertas y demandas.

Así, Osorio, Ramírez de la O y Viesca (2016) destacan cuatro ejes principales de las tendencias turísticas: desarrollo humano; estilos de vida; sostenibilidad y sus variables y; la competitividad y las TIC. Cabe destacar que las interacciones entre todos ellos fomentan la evolución hacia escenarios que pueden sorprender a muchos por su capacidad de cambio vertiginoso, y eso es un aspecto que corresponde afrontar a los gestores de ocio y de los destinos turísticos, poniendo en valor todo su potencial.

El desarrollo humano procura una evolución constante tanto en términos de ocio como turismo, ya que desarrolla e impulsa el crecimiento económico, sobre todo de muchos de los países en vías de crecimiento, donde en la mayor parte de los casos se espera que el principio de sostenibilidad tienda a estar presente desde un primer momento. Es ahí, en donde el fomento de los valores culturales que identifican el destino turístico representa una priorización, juntamente con la otra ventaja, la distribución de los retornos y beneficios económicos que la actividad turística pueda generar. Tampoco se puede confundir la distribución sostenible de los beneficios con la política de precios.

Otro aspecto a tener en cuenta hablando de las tendencias actuales, sobre todo en turismo, es el control de la capacidad de carga de un destino en concreto. Si no se gestiona correctamente, este hecho puede acarrear severas consecuencias, puesto que se corre el riesgo de llegar a sufrir el Síndrome de Venecia. Todos ellos son temas y aspectos que se consideran cruciales en la gestión turística y de ocio, tanto en los ámbitos nacionales como internacionales. 
Por otra parte, la identificación del destino turístico con el producto resulta imprescindible, tanto en tendencias como en demandas, de tal manera que resulta atractivo tanto para el turismo de audiencias domésticas como internacionales; y donde el binomio ocio-turismo se espera que esté omnipresente. Esta idea es a la que se denomina como autenticidad, un valor que de hecho no ha dejado de crecer desde los mismos inicios del fenómeno turístico.

La autenticidad y los viajes intergeneracionales emergen como otra de las tendencias inéditas. Se prevé una mayor afluencia de familias enteras, viajando juntas y compartiendo experiencias y emociones turísticas.

En esta línea, los estilos de vida, igual que los cambios demográficos y generacionales promueven igualmente los cambios constantes respecto a los gustos y las expectativas. Según el World Travel Market (2017) la mochila viajera es considerable, los viajes y desplazamientos, además de no dejar de crecer y se hacen mucho más cotidianos. En su Industry Report, el positivismo económico post crisis hace prever un aumento aún más espectacular que en años anteriores. Además, asegura el hecho de que la política de Trump no agrade a muchos de los posibles viajeros, y mencionan el ejemplo del Reino Unidoen el que el $27 \%$ de su población, elegiría otro destino en sustitución a Estados Unidos de América. Esta previsión puede dar paso a que otros destinos cercanos a esa distancia, aparezcan como posibles alternativas, mucho más respetuosas con todos los principios de sostenibilidad y de derechos humanos.

Otro de los aspectos que se han de introducir como otra de las nuevas tendencias hace referencia al uso del mismo concepto de experiencia que ya empieza a dejar paso al de emoción. Este último, apela más a un sentimiento interno y personal, más independiente de la repetición. La experiencia permite una ampliación extensísima de límites, que se hace cada vez mucho más evidente. 
En cuanto a los recursos humanos y su relación con las TIC, se constata una aproximación clara hacia lo que se puede considerar como la utilización de las nuevas tecnologías para facilitar la gestión burocrática y económica, como por ejemplo la realización de reservas. Aun así, queda mucho camino para poder hablar de sustitución de personas por audios como elemento personalizado de divulgación de la información o del acompañamiento. Estas personas, siguen siendo lo más valorado por el consumidor en el mercado puesto que garantiza la individualización y la exclusividad del servicio. En este sentido, un guía turístico acreditado no es comparable a un aparato de guía auditiva. El reto y el riesgo puede ir de la mano de la inmediatización del tiempo y de su liquidez de las que ya prácticamente todas las sociedades dependen.

Según el WTM (2017) Industry Report, se afirma que las micro aventuras seguirán aumentando en Europa, por lo que se puede prever una continuidad y crecimiento en la atención a las largas distancias, que juntamente a los valores propios de la sostenibilidad, del contacto con la naturaleza, de lo único, de lo auténtico, de esa idea de aventura única de "una-vez-en-la-vida", de la que también comenta Trekk Soft. Incluso del hecho turístico inminente, que las mujeres empiezan a viajar solas, por lo tanto, tiende aparecer como un importante y nuevo objetivo a tener cuenta.

Así todo ello, puede hacer que esos cambios mencionados y esperados, abran horizontes inéditos en propuestas para muchos posibles interesados en adquirir esas nuevas emociones, y que éstas se creen sin perder un ápice de la tan preciada identidad del destino turístico.

Las tendencias turísticas, son fundamentales para considerarlas en el desarrollo de productos. Para Puertas (2007) es hasta finales del siglo XIX que se puede hablar de un movimiento más o menos masificado y consciente de viajeros, el cual se vio favorecido por la revolución de los medios de transporte, por el conocimiento, la mayor disponibilidad de tiempo libre y una capacidad económica que va distribuyéndose más homogéneamente entre la población. De tal manera, los viajes empiezan a ser tomados como una posible fuente de beneficio económico.

Los estudios, la concienciación general y paulatina de que el tiempo dedicado al ocio es beneficioso para la persona, fomenta la idea de democratización y del ocio como un derecho de todo ser humano (ONU, 1948). Ayuda al desarrollo local que el turismo procura en el destino, asegura que esa concienciación se acelere y que genere una infraestructura, que dé respuesta a las necesidades de los viajeros. 


\section{e. Está naciendo la industria turística.}

Grandes estudiosos del ocio, con sus teorías, promueven en la segunda mitad del siglo XX sus beneficios (Neulinger, 1974; Iso-Ahola, 1980; Kelly y Godbey, 1992), y sobre todo Csikszentmihalyi (2001). "El ocio permite a las mentes desconectarse temporalmente de la realidad tal y como la contemplamos, para que emerjan nuevas posibilidades que serán posteriormente transformadas en realidad. Los antiguos griegos utilizaban la palabra scholé para referirse al tiempo libre, palabra que también significa aprendizaje, porque se consideraba como algo natural utilizar el tiempo libre para el desarrollo de la mente y tener mayor conocimiento del mundo" (Csikszentmihalyi, 2001 p.19).

(...) el ocio, desde un punto de vista individual, tiene mucho que ver con las vivencias de situaciones y experiencias placenteras y satisfactorias (Cuenca, 2000, p.15).

(...) La vivencia del ocio no depende de la actividad en sí misma, ni del tiempo, el nivel económico o en ocasiones, la formación que posea el sujeto de la vivencia. Sí tiene que ver con el sentido de quien la experimenta (Cuenca, 2000, p.15).

El ocio ya no es un lujo, es un derecho de todo ser humano. Y es por ello que, desde la revolución industrial, se han creado tiempo de descanso, como los días libres y vacaciones que permite a las personas desarrollar actividades de Ocio.

Según la Declaración Universal de Derechos Humanos (ONU, 1948), el Artículo 24: Toda persona tiene derecho al descanso, al disfrute del tiempo libre, a una limitación razonable de la duración del trabajo y a vacaciones periódicas pagadas.

Entre todas las actividades y vivencias de ocio destaca el turismo, que permite al individuo vivenciar nuevas experiencias, disfrutar, desconectarse del trabajo y "recargar baterías" para enfrentar de mejor manera su vida cotidiana y laboral. Es por ello, que hoy en día es una de las actividades económicas más importantes e imprescindibles del globo.

Una de las funciones más importantes en la gestión de destinos es el uso que se hace de los atractivos de los que dispone el lugar. Uno de los modelos más utilizados, y avalado por la OMT, ha sido el de Swarbrooke (1998), quien estructura 4 ámbitos de análisis definiendo cada uno de ellos. Sin embargo, y desde su aplicación en un destino turístico como 
puede ser el litoral de la costa catalana, en el noreste español, se echaba de menos otro posible ámbito. Para el XX World Leisure Congress Quebec, Canadá, organizado por el World Leisure Organization, en el 2008, se presentó la ponencia"Ethics and cultural mediation in the tourist area. The mediators of tourist leisure and the tourist entertainer" (Puertas, 2008). En ella se proponía ese otro ámbito, un quinto, denominado ámbito de escaneo de un territorio. Logrando así contar con cinco ámbitos para el análisis de los atractivos, los cuatro primeros correspondían al autor suizo John Swarbrooke y éste último propuesto por Xavier Puertas.

Esquema 2. Escaneo para un territorio.

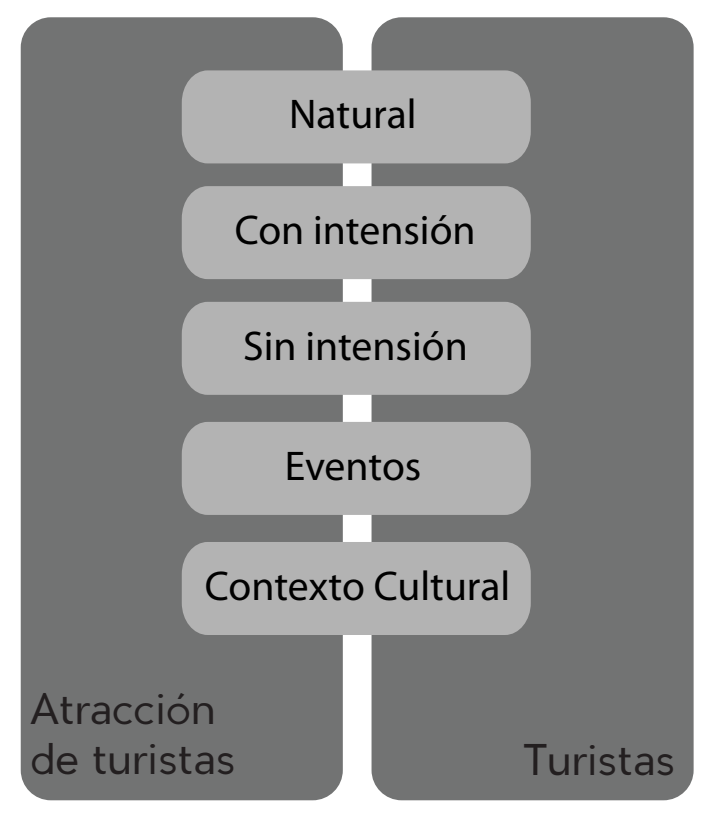

Fuente: Adaptado de Puertas (2008).

Los gestores turísticos han de poder dar un uso responsable a sus decisiones estratégicas en su función de mediación entre los atractivos turísticos y los turistas, tal y como se ejemplifica en el esquema 1. Por tanto, se sitúan en medio de ambos y con su acción se hacen responsables de los usos y de sus consecuencias. 
Para un escaneo efectivo de un territorio, seguir este modelo significa que se podrá detectar cualquier posible atractivo con posibilidades de convertirse en argumento para la creación de un flujo. Sin embargo, no son excluyentes, es decir, que puede darse el caso de que un atractivo pueda estar en dos ámbitos diferentes. No es grave, de lo que se trata, es de buscar la razón por la que se incluye en uno de ellos y no en el otro. Lo más importante es que, éste en un ámbito o en otro, el atractivo quedará reflejado en la lista del catálogo de posibilidades.

El turismo supone acceso a gran cantidad de personas, quienes en principio deben tener derecho al ocio, por lo tanto es una actividad que disfrutan los diferentes extractos sociales. Sin embargo, la accesibilidad a los diferentes sitios se da en función de una marcada diferencia del poder adquisitivo de las personas. Claro está en Costa Rica, que a menor nivel económico la visitación se da a sitios públicos o lugares de menor costo, esto en el caso del turismo nacional. Con lo anterior se relaciona el turismo social, el cual tiene como característica los servicios de gastos reducidos, el uso de transporte público, entre otros.

La sostenibilidad, es un tema que está intrínseco en la actividad turística, la implementación de acciones en función de la sostenibilidad, se visualiza más claramente en el sector privado, ya que ello implica un tema de competitividad en el mercado. Aunque en la actividad turística están involucrados tanto el sector público como privado. El sector público requiere hacer acciones en función de ello, ya que debe responder a políticas públicas y la sostenibilidad es una de ellas. Para ello, se requiere que se haga una adecuada gestión y ejecución de recursos.

El ocio es una actividad, que le permite al ser humano distraerse y ubicarse mentalmente en un contexto diferente, donde desarrolla la mente y adquiere mayores conocimientos. El ocio se refiere al uso del tiempo libre de diversas formas, por lo que no necesariamente va a implicar un costo, ello se refiere a que tiene una orientación más marcada en la experimentación de vivencias. Su relación con el turismo es que también implica descanso en días libres, pero en ésta prevalece el pago de servicios. 
Los sitios visitados en la investigación, están ubicados en diferentes lugares del país, cuyas características territoriales son diversas, donde se encuentran los atractivos naturales, atractivos con intención y sin intención, eventos y contextos culturales. La diversidad de los atractivos fortalece la oferta turística, en algunos de los casos su desarrollo ha sido de manera espontánea inicialmente y en otros de forma planificada, tanto desde el seno de la unidad productiva, como en el destino turístico.

Las diez categorías de análisis propuesta en este artículo, refleja la riqueza turística que posee el país, con una clara orientación de productos y servicios que se complementan entre sí, considerando la aventura, la naturaleza, la historia, el patrimonio, la cultura, entre otros. Esto es el resultado de un claro aprovechamiento de los recursos con que se cuenta y una visión de desarrollo que ha beneficiado a gran parte de la población nacional, tanto en sitios rurales como urbanos.

Las tendencias del ocio y el turismo se orientan hacia la sostenibilidad, enmarcado en los aspectos económicos, sociales y ambientales, en lo cual se viene trabajando hace algunos años, pero en la actualidad se continúan con mayores esfuerzos fortaleciendo la oferta turística. Un aspecto que es importante a rescatar, es la contribución de esta actividad al desarrollo humano, lo cual ha fomentado crecimiento y cambios en los estilos de vida.

Es fundamental que el turismo se desarrolle con una adecuada gestión, especialmente en lo que se refiere a la planificación de los destinos turísticos, considerando principalmente la capacidad de carga de los sitios más sensibles a la visitación, cuyo impacto negativo tanto en aspectos sociales como ambientales, se pude mermar de manera oportuna.

Los turistas actualmente, lo que buscan son experiencias, en ese sentido es necesario que los servicios estén acompañados de una gran cantidad de valores agregados que fundamenten más la experiencia.

El uso de las nuevas tecnologías es una de las grandes tendencias, la cuales han facilitado de manera oportuna la operación comercial de las empresas turísticas, especialmente por la reducción de costos, la agilidad en la respuesta y que se acortan distancias. La tecnología viene a complementar los servicios, en los cuales siempre prevalece la personalización, ya que el contacto entre las personas implica un gran valor en el servicio. 


\section{ABORDAJE METODOLÓGICO}

Por tratarse de una investigación sobre la situación actual del ocio y turismo sostenible en el país, se diseñó una metodología cualitativa y cuantitativa, debido a que ambas permiten profundizar en el objeto de investigación. Sin embargo, por las características de la misma posee un énfasis más marcado en lo cualitativo.

La metodología cualitativa lo que procura es analizar una serie de aspectos particulares del ocio y el turismo del país, haciendo una combinación de elementos históricos, actuales y tendencias. Por lo tanto, los resultados de la investigación, van a reflejar comentarios de las vivencias en el trabajo de campo con los actores involucrados en la actividad turística, los cuales fueron entrevistados para tal fin.

Un aspecto relevante en el proceso metodológico es la observación por parte del equipo de investigación, la cual permitió un acercamiento particular al objeto de estudio y a su vez, una mayor compresión de la situación actual del ocio y del turismo sostenible.

Parte de la estrategia metodológica fue hacer una selección de las categorías de análisis, con el propósito de seleccionar de mejor manera los sitios a visitar. Las categorías de investigación se definieron bajo el criterio de expertos, estas son las siguientes:

\section{Categorías de análisis}

a. Sitios históricos y patrimoniales

b. Actividades culturales programadas

c. Espacios acuáticos

d. Sitios de atracción cultural

e. Sitios de atracción natural

f. Servicios turísticos con actividades de entretenimiento

g. Recreación y esparcimiento

h. Actividades de aventura

i. Sitios de educación natural y cultural

j. Rescate de animales silvestres 
a. Sitios históricos y patrimoniales: Lo constituyen propiedades inmuebles, edificios singulares, instalaciones industriales, casas conmemorativas de personas notables del pasado, monumentos, cementerios y tumbas, sitios arqueológicos y paisajes culturales -entornos artificiales y hábitats naturales significativamente alterados por el ser humano-, hechos por el hombre e importantes desde el punto de vista histórico o cultural, presentes en el territorio de un país y cuyo valor como patrimonio ha sido reconocido mediante un proceso oficial de selección e identificado y registrado por separado(Centro de Investigación y Conservación del Patrimonio-MCJ, S.F.).

b. Actividades culturales programadas: son actividades de índole religioso o cultural que se celebran una vez al año, en fechas predeterminadas. Estas actividades son organizadas por asociaciones comunitarias, instituciones, gobiernos locales, entre otros; vinculadas con los temas de interés. El propósito de estas actividades son mantener y promover la cultura local en las diferentes generaciones del país y una de sus principales características es que son dirigidas a todo el público y gratuitas.

c. Espacios acuáticos: son sitios donde se le da diferentes usos al recurso hídrico, entre ellos la práctica de algún deporte acuático, ya sea natación, kayak o para distracción. Estos espacios se presentan en piscinas, cascadas, aguas termales, otros. Una de sus principales características, es que son lugares atractivos para el disfrute familiar.

d. Sitios de atracción cultural: Chang, G. (2016, p. 46) menciona que el patrimonio cultural "se vincula con la herencia de hechos culturales que un grupo considera como bienes propios, que son compartidos por una comunidad y actúan como referente identitario. El reconocimiento y la valoración de un determinado bien cultural, por parte de la colectividad que lo produce, implican un proceso -muchas veces inconsciente- de jerarquización y selección entre una amplia variedad de hechos culturales".

e. $\quad$ Sitios de atracción natural: Chang, G. (2016, p. 45) indica que "Se ha llamado patrimonio natural a bienes como la biodiversidad (cifrada en las especies de flora y fauna), los distintos ecosistemas regionales, las playas, los volcanes, los bosques, los ríos, las sabanas, las lagunas, los mares, los cerros y las montañas." 
f. Servicios turísticos con actividades de entretenimiento: turismo de placer o recreo. Según los analistas del ocio como Cuenca (2004), Lázaro (2006), Stebbins (2004) y Csikszentmihaly (2001), podría significar la realización de la persona según las preferencias y condicionantes personales los que le incitan a desplazarse para conseguir esa experiencia inédita y única que más le satisface. En esta línea, Csikszentmihaly asegura que no hay límites en esta óptica esotérica. Es su teoría del "Fluir", como recompensa máxima de la satisfacción de las necesidades de ocio personales. La variedad de viajes es amplísima, asegura Quesada (2014), y cuyo fin principal es el deseo de divertirse y disfrutar, como dice Stebbins en su "Ocio Serio". No hay más razón que la mera satisfacción de hacer lo que más te gusta.

g. Recreación y esparcimiento: aunque las posibilidades de que un destino se posicione únicamente basado en la oferta de entretenimiento, es poco probable Fletcher, Fyall, Gilbert, y Wanhill (2007). Sin embargo, hay que reconocer que un destino sin una oferta consistente de entretenimiento, resulta igualmente inimaginable. El destino ha de gestionar un abanico amplio de posibilidades de actividades en las que aparezcan de todo tipo, no solo las de entretenimiento, la variedad ya no es una opción. Solo hay que revisar de nuevo las teorías de Stebbins o de Csikszentmihaly.

h. Actividades de aventura: Actividades turísticas de alto riesgo o dificultad conforman esta modalidad. El Instituto Costarricense de Turismo las define como " aquellas actividades recreativas que involucran un nivel de habilidades físico - deportivas con riesgo identificado y en contacto directo con la naturaleza, dentro de las cuales se clasifican, entre otras, las siguientes actividades": a) canopy tour; b) skywalk o skytrek, c) bungee jumping, d) balsas en ríos - white water rafting, e) buceo - scuba diving, f) descenso con cuerdas - rapel, g) escalar, h) ciclismo, navegación con kayak por mar o rio, otros (Quesada, 2014, p. 113).

i. Sitios de educación ambiental y cultural: Como un aspecto muy concreto y determinante de las propuestas culturales, y de su capacidad pedagógica que según Neulinger (1974), se podían asociar a las actividades de ocio, la educación entendida como el fomento del conocimiento, con una clara función pedagógica, es una parte indiscutible de las propuestas de ocio en la actualidad. Cuenca (2004) también lo recoge en su obra dedicada a la pedagogía del ocio. De esta forma, las propuestas que incluyen el fomento y desarrollo de la educación natural o cultural, se pueden incluir en este grupo de análisis. Son atractivos con 
intención, en este grupo de atractivos se incluyen aquellos que se han edificado con la clara intención de ser eso, un atractivo para ser visitado. En esta línea se pueden incluir, aunque pueda dar lugar a discrepancias, los centros de interpretación que se pueden encontrar en algunos parques, espacios protegidos o incluso en parques naturales. Tampoco se pueden confundir con los centros de información turística genérica $o$ con los puntos de venta de recuerdos o artesanías, ya que en todos los casos son complementos que facilitan la visita y la divulgación de valores a los visitantes.

j. $\quad$ Rescate de animales silvestres: Son lugares que ofrecen refugio a animales heridos, maltratados, confiscados, abandonados 0 desplazados. En estos lugares se les alimenta y se les da tratamientos médicos, dependiendo de la condición de cada animal, algunos son reinsertados a la naturaleza una vez que estén rehabilitados. Generalmente, los lugares de rescate de animales silvestres trabajan con proyectos, voluntariado y donaciones de organizaciones o personas sensibles al tema de rescate animal.

En el proceso de recolección de información, se hizo, tanto de fuentes primarias como secundarias. En el caso de las fuentes primarias se hizo entrevista a informantes claves de los distintos servicios que se visitaron, en algunos casos a las personas propietarias o sus colaboradores. La entrevista se diseñó a partir del criterio de expertos y se validó con el equipo de investigación. En el caso de las fuentes secundarias se acudió a documentación la cual sustentó principalmente la parte teórica. Los instrumentos utilizados fueron:

1. Entrevista semi-estructurada: se elaboraron una serie de preguntas, sin embargo, durante la entrevista se generó un diálogo espontáneo con las personas informantes, lo que permitió enriquecer aún más la información recolectada.

2. Observación: la observación de las personas que realizaron el trabajo de campo, permitió fortalecer la información suministrados por las personas informantes claves.

3. Análisis documental y bibliográfico: para ello se recurrió a diferentes fuentes de información tales como documentos, estadísticas, publicaciones, otros. Ello permitió fundamentar más el marco teórico de la investigación. 
Para la fase final de la investigación, se hizo una triangulación de la información, la cual consiste en una comparación del material teórico con los resultados de la investigación.

El universo de estudio de la investigación es amplio, debido a que está compuesto por servicios y atractivos turísticos. Se visitaron 62 lugares y en el análisis se incluyeron 5 actividades culturales programadas. La fecha de celebración de éstas, no coincidió con el trabajo de campo, pero si se consideraron dentro del análisis. Por lo tanto, el universo total de estudio es 67.

En el siguiente cuadro, se presenta el nombre de cada sitio visitado y agrupado por categoría.

Cuadro 2. Categorías de análisis y sitios involucrados

\begin{tabular}{|c|c|}
\hline Categoria & Subdimensión \\
\hline \multirow{7}{*}{$\begin{array}{l}\text { Sitios } \\
\text { históricos y } \\
\text { patrimoniales }\end{array}$} & Monumento Nacional Guayabo \\
\hline & Sitio Arqueológico Finca 6 \\
\hline & Fortín de Heredia \\
\hline & Ruinas de Ujarrás \\
\hline & Iglesia y museo de Orosí \\
\hline & Sanatorio Durán \\
\hline & Parque Nacional Santa Rosa \\
\hline \multirow{5}{*}{$\begin{array}{l}\text { Actividades } \\
\text { culturales } \\
\text { programadas }\end{array}$} & Día del Negro \\
\hline & Día de la Mascarada (Barva, Cartago y Aserrí) \\
\hline & La Virgen del Mar \\
\hline & El día del Boyero \\
\hline & Romería a la Basílica de Los Ángeles \\
\hline \multirow{4}{*}{$\begin{array}{l}\text { Espacios } \\
\text { acuáticos }\end{array}$} & Balneario Ojo de agua \\
\hline & Balneario Los patios \\
\hline & Blue Day Family Club \\
\hline & Parque Acuático La Boya \\
\hline
\end{tabular}




\begin{tabular}{|c|c|}
\hline \multirow{6}{*}{$\begin{array}{l}\text { Sitios de } \\
\text { atracción } \\
\text { cultural }\end{array}$} & La Casona Río Fortuna \\
\hline & Los Mantudos \\
\hline & Finca Naval Micro beneficio Verde Pittier \\
\hline & Basílica de Los Ángeles \\
\hline & La Casona - San Vito de Coto Brus \\
\hline & Comunidad de Barba de Heredia \\
\hline \multirow{12}{*}{$\begin{array}{l}\text { Sitios de } \\
\text { atracción } \\
\text { natural }\end{array}$} & Playa Jacó \\
\hline & Paseo de los turistas \\
\hline & Mirados Ujarrás \\
\hline & Mirador Orosí \\
\hline & Represa de Cachí \\
\hline & Parque Nacional Volcán Poás \\
\hline & Cataratas de La Paz \\
\hline & Laguna Hule \\
\hline & Parque Prusia \\
\hline & Cataratas Llanos de Cortés \\
\hline & Finca Cántaros \\
\hline & Parque Nacional Carara \\
\hline \multirow{6}{*}{$\begin{array}{l}\text { Servicios } \\
\text { turísticos con } \\
\text { actividades de } \\
\text { entretemiento }\end{array}$} & Paraíso del Quetzal \\
\hline & Tuchas y El Gavilán \\
\hline & Rancho del Sapito \\
\hline & Blue River Resort \\
\hline & Centro Eco turístico Los Robles \\
\hline & Lagos Doña Ana (Cerro de la Muerte) \\
\hline
\end{tabular}


Recreación y

esparcimiento
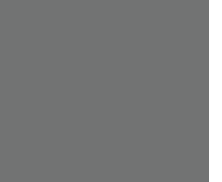

Actividades

de Aventura

Sitios de

educación

natural y

cultural

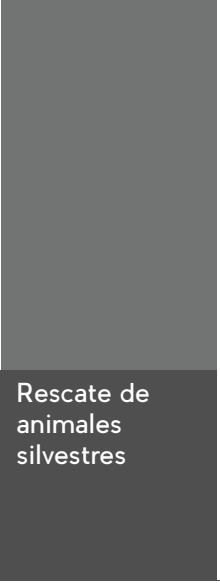

Parque recreativo Charrarra

Paradero Turístico Playas de Doña Ana (Puntarenas)

Parque del Este

Parque la Sabana

Parque La Paz

Bosque de la hoja

Monte de la Cruz

Parque La Expresión Laguna Doña Ana Cleto

Parque Recreativo Cariari

Centro Recreativo Las Musas

FossilLand

Hotel Monte Campana

Parque Sapito entre Volcanes

Místico Arenal Hanging Bridges Park

Hacienda El Cenízaro

Sky Adventures Arenal Park

Ponderosa Adventure Park

Parque La Libertad

Magmática

Finca Educativa Don Juan

Jardín Botánico Wilson y Estación Biológica Las Cruces

Jardín Botánico Lankester

Veragua Rainforest Park

Ecocentro Danaus

Sloth Sanctuary

Centro de Rescate Jaguar

Santuario de Vida Silvestre Alturas

Fuente: Elaboración propia (2018). 


\section{RESULTADOS}

Seguidamente, se presentan los resultados por cada una de las categorías de análisis.

Los sitios históricos - patrimoniales contemplados en la investigación poseen una serie de aspectos positivos, entre ellos la riqueza histórica. Para efectos de visitación, estos lugares reúnen una serie de condiciones básicas que se encuentran en buen estado. Por ejemplo, la accesibilidad de los colaboradores, la higiene, el servicio al cliente, las condiciones físicas son aceptables, la seguridad en cuanto a personal y al visitante se refiere, así como accesibilidad del lugar tanto para niños, adultos y adultos mayores. Estas condiciones favorecen que el lugar sea mayormente visitado. Por ejemplo, en un $71 \%$ de estos sitios las condiciones de higiene, garantiza la seguridad del de los visitantes. A pesar que los sitios históricos - patrimoniales poseen una serie de aspectos positivos, requieren de algunas mejoras en los servicios. Por ejemplo, la rotulación tanto en la entrada como en las áreas comunes, en algunos casos se encuentra en malas condiciones y en otros, es muy escasa.

La rotulación es importante porque brinda una serie de información al visitante en cuanto a horarios, condiciones de comportamiento, precios, entre otros, que orientan al turista. Otra debilidad que se presenta en estos sitios son las condiciones físicas de accesibilidad para personas con alguna condición especial, por ejemplo se carece de letreros para personas que tenga limitación con la visión. También se identificó que no hay una política en estos lugares de brindar una mejor atención a personas que tengan alguna discapacidad. El 29\% de los sitios están mal con respecto a este tema. Si bien es cierto no es un porcentaje mayoritario, todos los lugares de turismo deben de velar por ser inclusivos. Los sitios históricos patrimoniales se caracterizan por la falta de involucramiento de los actores locales en estos lugares. Es necesario incluirlos, porque pueden contribuir al fortalecer los lugares y darles algún valor agregado. 
Imagen 1. Sitio Arqueológico Finca 6

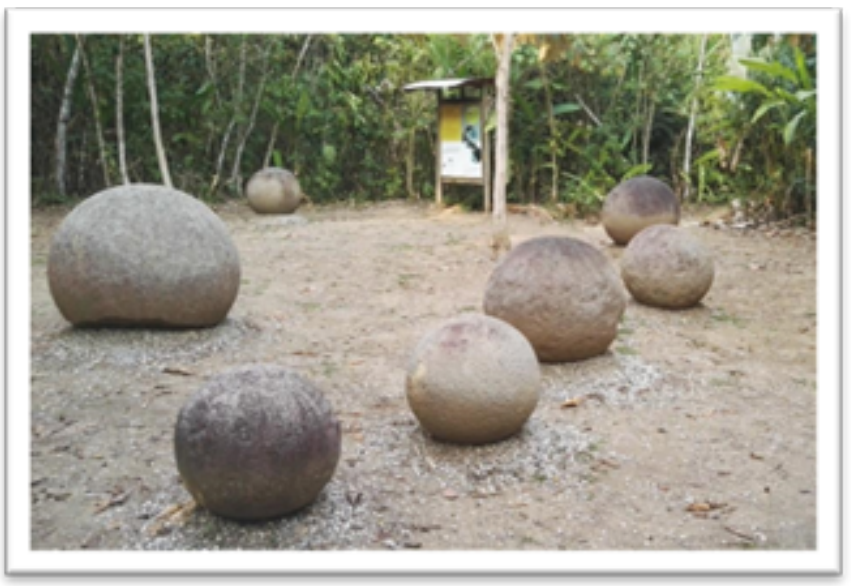

Fuente. Fotografía de Yorlenny Fontana Coto (2018).

Las actividades culturales programadas son visitadas mayoritariamente por los costarricenses; sin embargo, por su contenido cultural son actividades que se deben promocionar para que sean visitadas por los turistas extranjeros, ya que en estos espacios se refleja gran parte de la identidad del costarricense. Es por ello que se hace necesario que el ente rector destine recursos promocionales y dé apoyo a estas actividades. En el país se celebran varias actividades culturales programadas, algunas de ellos son:

a. El Día del Negro y la cultura Afro-costarricense: se celebra el 31 de agosto de cada año. La celebración, tiene como propósito que se reconozcan los aportes de la población Afro-costarricense, en igualdad de condiciones con respecto a los aportes económicos, sociales y culturales que han dado al país. Ese día se caracteriza por una fuerte manifestación de expresiones culturales, folklóricas, artísticas, religiosas, entre otras, relacionadas con la cultura negra. La tradición es el Grand Parade, que es el desfile por las principales calles de la provincia de Limón, que resalta, los trajes, carrozas, música y bailes que disfrutan tanto niños, jóvenes, adultos y adultos mayores. Detrás de la celebración, está la historia del afro-costarricense, formadas por hombres y mujeres, de luchas, logros y esperanzas. El trabajo ha contribuido mucho al desarrollo económico y su aporte cultural al país, y hoy día al igual que sus antepasados continúan enriqueciéndolo y mostrando el valor y el respeto de la diversidad étnica de Costa Rica. 
b. El día de la mascarada: en 1996 el gobierno de Costa Rica firmó un decreto para declarar el 31 de octubre de cada año el Día de la Mascarada Tradicional Costarricense, con el objetivo primordial de promover el conocimiento de las diferentes manifestaciones culturales existentes en el país, el propósito es recuperar y consolidar la identidad cultural del costarricense. El origen de esta tradición, se remonta a la época colonial del país, la cual es una combinación de las festividades españolas con la influencia de las festividades indígenas. Esta tradición fue heredada a las fiestas patronales de los pueblos de Costa Rica, donde se hacen festividades religiosas para celebrar el patrón del pueblo. Esas celebraciones son los llamados "turnos", donde se venden comidas, realizan juegos de azar, rifas, subastas de ganado y productos agrícolas. El referente de las mascaradas en un pueblo es el sonido de las bombetas y las cimarronas. Los personajes característicos de las mascaradas son referidos por las leyendas del país, como lo son el Padre sin Cabeza, la Llorona, el Cadejos, la Segua, la Muerte, la Giganta, entre otros. Sin embargo, con el paso del tiempo se diseñan personajes más de índole comercial. En la mayoría de las comunidades de Costa Rica las mascaradas son una gran tradición y los lugares donde en la actualidad se celebra con gran entusiasmo es en Cartago, Barva de Heredia, San Antonio de Desamparados, Aserrí y Escazú.

c. La Virgen del Mar: es una celebración religiosa que se lleva a cabo el 16 de julio en Puntarenas. La celebración consiste en un desfile de embarcaciones de diferentes características, las cuales son adornadas con diferentes artículos y desfilan frente a las playas de Puntarenas en el Golfo de Nicoya. El desfile dura aproximadamente 3 horas. Una de las embarcaciones transporta a la Virgen del Monte Carmelo. Como parte de las tradiciones, se hacen misas, conciertos, actividades culturales, deportivas y fuegos artificiales. La historia de la celebración es que en 1913 naufragó el barco denominado "El Galileo" con toda la tripulación cerca de la Isla del Caño, los familiares de la tripulación se dirigen a la iglesia a pedirle a la Virgen del Carmen por los tripulantes. Días después llega la noticia que los tripulantes son trasladados a Puntarenas por un barco que los rescató. La historia, también dice que la Virgen del Carmen era la protectora del pueblo puntarenense desde hacía varios años. Los documentos que hacen referencia a esta historia describen que los tripulantes de "El Galileo" recibieron ayuda de una mujer, esto después de haber caído al mar. Cuentan que esta mujer los alimentó, los protegió y les dio fuerza para sobrevivir. 
d. Día del Boyero: es una celebración que se realiza en varias partes del país, todos los años el día 14 de marzo, las carretas y los bueyes desfilan por las principales calles de cada lugar donde se acostumbra hacer. En las carretas van por lo general niños con trajes típicos, cargadas de frutas y verduras. Desde el 2005, la actividad del boyero se convirtió en Patrimonio Intangible de la Humanidad, por parte de la UNESCO. La carreta y los bueyes forman parte de la historia del costarricense, debido a que se utilizaban como transporte para el café, los agricultores trasladaban el cultivo del Valle Central a los puertos para exportación y también era un medio de transporte familiar. En ocasiones se reúnen los boyeros de varias partes del país y desfilan en la ciudad capital, es ahí donde se puede observar algunos rasgos característicos del tipo de carreta que por los colores o decoración se diferencian. Además, la carreta es un símbolo nacional de la herencia cultural del país.

Escazú es uno de los lugares donde tradicionalmente se hace la celebración; a parte del desfile, se desarrollan diferentes actividades como fuegos artificiales, mascaradas, música y bailes folclóricos y degustación de comida típica.

Romería a la Basílica de los Ángeles. Según la Catholic.Net (2018) "La Virgen de los Ángeles fue declarada patrona de Costa Rica por el Papa Juan Pablo II. La devoción a la Virgen de los Ángeles tiene una mezcla de características entre la tradición cristiana-europea con elementos de la cultura indígena y negra. La tradición de la romería, se celebra desde finales del siglo XIX el 2 de agosto hacia la Basílica de los Ángeles en el casco urbano de la provincia de Cartago. Las personas que participan de la romería lo hacen desde diferentes partes del país, incluso personas de otros países participan de esta actividad.

La leyenda dice que el 2 de agosto de 1635 una joven mulata llamada Juana Pereira iba a recoger leña como de costumbre y se encontró, en medio del bosque, una pequeña estatua de una muñeca con un bebé en brazos, la Virgen María. Según se cuenta en la historia oral, la imagen estaba sobre una roca cerca de un manantial, en el lugar llamado la Puebla de los Pardos. Juana Pereira decidió llevársela para su casa, donde la guardó en un cajón envuelta en un paño de tela. Al día siguiente, Juana volvió al sitio del primer hallazgo y se encontró una muñeca de piedra igual a la encontrada el día anterior, hizo lo mismo, se la llevó para su casa, para guardarla junto a la otra. Pero cuando llegó a buscarla se dio cuenta que la imagen no estaba, así volvió a guardarla encontrada nuevamente, lo mismo sucedió al tercer día. Esta vez se la llevó al sacerdote de la localidad, Alonso de Sandoval, quien la guardó 
en una caja, y se olvidó de ella. Al día siguiente abrió la caja y, para su sorpresa, no estaba. Juana Pereira volvió al lugar de las apariciones y encontró ahí la imagen, así que se la llevó al sacerdote y este la guardó dentro del sagrario. Al día siguiente abrió el sagrario y no la encontró, por lo que declaró que aquello era un mensaje de la Virgen. Ella deseaba estar en el bosque, sobre la roca, por lo que construyeron un pequeño templo en su honor, donde actualmente se encuentra la Basílica de los Ángeles. La imagen fue bautizada como Virgen de Los Ángeles, porque el 2 de agosto los franciscanos celebran la fiesta de Nuestra Señora de los Ángeles. Las personas que hacen la romería lo hacen para pedir o pagar por algún milagro. Conforme han pasado los años la cantidad de romeros ha aumentado sustancialmente.

Espacios acuáticos: Los espacios acuáticos visitados, se caracterizan por ser lugares de esparcimiento su gran atractivo son las piscinas. Sin embargo, también poseen otros atractivos como lo son toboganes, cascadas, restaurantes, nacientes de agua, áreas de juegos para niños, canchas para practicar diferentes deportes como futbol, voleibol, tenis, patinaje, aeróbicos, kayak, etc. Así como quioscos o ranchos para para comer. Estos lugares son Ojo de Agua, Balneario Los Patios, Blue Day family club y la Boya.

Estos lugares, se caracterizan por ser espacios amplios para el disfrute familiar, propician el desarrollo de actividades grupales, cuentan con buenas condiciones de acceso y de una caseta donde se brinda información primaria. En general, son lugares atractivos y con condiciones físicas aceptables. Sin embargo, algunas debilidades en la parte física, es que no existen las condiciones adecuadas para el traslado de personas con alguna discapacidad, faltan barras de apoyo y demarcación de aceras y rotulación.

Otro de los aspectos en que se debe mejorar es el manejo ambiental de los lugares, debido a que los esfuerzos en esta materia no son tan visibles y en algunos de los casos donde sí los hay, los usuarios no colaboran, por lo que es importante suministrar mayor información para ofrecer educación en esta materia a los visitantes. En ninguno de los sitios se hace un rescate de la cultura local, lo cual es un vacío notorio que, aunque estos sitios están dirigidos al turista nacional, es importante el fomento de la cultura a través de la gastronomía y actividades en general. Una de las grandes ventajas es que las personas pueden llevar sus propios alimentos, a pesar de que en algunos casos tiene restaurante. Esta situación en particular permite que los lugares sean más accesibles en términos económicos para las familias costarricenses de clase baja y media, principalmente. 
Los sitios de atracción cultural, son lugares que carecen de políticas visibles de manejo ambiental, por lo que deben hacer esfuerzos fuertes en este sentido. Estos lugares sí cuentan con muy buenos aspectos culturales, al ser el elemento principal del producto turístico que ofrece. Los sitios de atracción cultural, sin duda alguna son un recurso que forma parte importante de los productos turísticos que ofrece el país, entre ellos se encuentran servicios de gastronomía, mascaradas, actividades tradicionales campesinas como cogidas de café, trapiche, etc. También, se convierten en un importante recurso cultural lugares como la Basílica de los Ángeles y el Parque Nacional Santa Rosa, éste último principalmente por su legado histórico en el proceso de independencia de Costa Rica del filibusterismo del siglo XIX. En cuanto a las condiciones de ingreso estos sitios cuentan con adecuada rotulación, accesibilidad de colaboradores, seguridad e higiene. Se cuenta con espacios amplios para el disfrute de las personas y la mayoría de ellos con áreas de diferentes ambientes familiares propiciando el desarrollo de diversas actividades. Los sitios mencionados tienen en común que poseen una herencia cultural y que a nivel de comunidad o de empresa han tenido la iniciativa de impulsarlo e insertarlo en la actividad turística. Una de las grandes ventajas que ha generado esta actividad económica en el país, es que ha propiciado que los aspectos culturales de la población se revaloricen por los mismos costarricenses. En el caso de la Casona Rio Fortuna y de la Finca Naval Verde Pittier, reúnen las condiciones físicas aceptables en cuanto a seguridad y acceso para los visitantes. En el caso de los mantudos, es un taller de mascaradas que por sus características propias está en condiciones de recibir turistas, pero en grupos pequeños. En estos lugares se carece de políticas visibles de manejo ambiental, por lo que deben hacer esfuerzos fuertes en este sentido. A pesar de ello, se encuentran en muy buenas condiciones, los aspectos culturales, es el principal producto turístico que ofrece. En cuanto a la Basílica de Los Ángeles, la comunidad de Barva y la Casona, son sitios que por sus actividades religiosas o culturales atraen automáticamente a los turistas por el recurso y la tradición que poseen en el tema cultural. Sin embargo, tanto las empresas como las comunidades antes mencionadas requieren involucrar aún más a los actores locales para fortalecer y potenciar el producto turístico cultural.

Los sitios de atracción natural son muy diversos por sus propias características, los cuales al igual que los sitios de atracción cultural, son elementos fundamentales de los productos turísticos que ofrece el país, entre ellos hay playas, Parques Nacionales, cataratas, volcanes, entre otros. La característica común de estos lugares es que están al aire libre, son espacios abiertos, lo que propicia que haya una fuerte interacción entre la naturaleza y los visitantes. Además, que reúne las condiciones para 
que las personas desarrollen diversas actividades, tales como caminatas, observación de flora y fauna, hacer fotografías, tomar un baño, etc. Una ventaja de estos lugares es que los espacios cuentan con condiciones aptas para personas de diferentes edades. Los factores a mejorar de los lugares son la rotulación en aspectos de seguridad, especialmente para que se anuncie sobre las condiciones riesgosas de los sitios, con un sentido más de prevención.

La mayoría de estos lugares se encuentran relativamente cerca de la ciudad capital, excepto Llanos de Cortés y Finca Cántaros, lo cual es ventajoso para el turismo nacional porque puede disfrutar de un día de esparcimiento natural y a un costo relativamente bajo. En la mayoría de los aspectos valorados de estos lugares, cuentan con condiciones adecuadas de: facilidad de trasladarse de un sendero a otro, condiciones de los caminos de acceso a los lugares, rotulación visible y casetas de información. Tanto en aspectos ambientales en lo referente a los depósitos de basura, así como la higiene de los lugares, tuvo calificación de bueno a excelente, lo cual es muy buen indicador. Sin embargo, las acciones en estos temas son constates y hay que trabajarlos para mantenerlos en buenas condiciones.

Con respecto a los servicios de alimentación, varios de estos lugares reúnen las condiciones para tal fin. En algunos de los casos se cuentan con áreas para comer, o bien para hacer parrilladas y otros que no cuentan con estas características se pude ingresar con alimentos. Sin duda alguna, en los lugares que se tienen condiciones para llevar comida, se hacen más accesibles para las familias.

Los servicios turísticos con actividades de entretenimiento son empresas de turismo que además de brindar los servicios básicos como en algunos de los casos hospedaje y alimentación, ofrecen algunas otras actividades o servicios complementarios que se convierten en entretenimiento para las personas visitantes. Con la Ley 7600 (Ley de igualdad de oportunidades para las personas con discapacidad), las empresas e instancias involucradas en el turismo han hecho esfuerzos en el cumplimiento de ésta. Sin embargo, aún falta mucho trabajo qué hacer para que la actividad turística sea realmente inclusiva. Adicionalmente, se detectó una gran debilidad, debido a que tampoco las empresas hacen esfuerzos en propiciar actividades recreativas adaptadas a personas con alguna discapacidad física. 
En términos generales, con respecto a las características de los lugares referentes a la rotulación, casetas de información, accesibilidad a colaboradores, información para el turista e higiene, la valoración de estos lugares es positiva ya que sus calificaciones fueron entre excelentes y bueno. Estos sitios se caracterizan porque los visitantes pueden hacer no una, sino varias actividades en el mismo lugar, lo cual es una ventaja económica para los empresarios ya que el cliente consume más en el sitio. Entre las actividades están la pesca de trucha, observación de aves, caminatas, cabalgatas, uso de piscinas, observación de flora y fauna, entre otras. Estos lugares poseen varios espacios recreativos para el entretenimiento de las personas visitantes y en todos los sitios se encuentran en buenas condiciones. Con respecto al tema de seguridad, un $25 \%$ de las empresas debe mejorar especialmente en la elaboración y aplicación del plan de emergencias, así como en el uso de dispositivos complementarios de seguridad.

Estas empresas tienen las condiciones para promover la cultura local. Sin embargo, eso no se refleja en los resultados de la investigación, no se evidenció información cultural, tampoco de gastronomía, ni de actividades relacionadas con la cultura, lo que muestra una gran debilidad en este sentido.

Los sitios de recreación y esparcimiento son lugares que se caracterizan por ser visitas de un día, donde las personas tienen la posibilidad de recreación haciendo diferentes actividades en un solo lugar. Algunas de estas actividades son práctica de deportes acuáticos, diversidad de juegos para niños, lugares aptos para comer y compartir en familia.

El común denominador de estos lugares es que en términos de ubicación son lugares muy accesibles; algunos de ellos son a bajos precios y en otros no cobran, por lo que los precios oscilan entre 0 a $\$ 3500$ (\$USD 5,6 aproximadamente). Estas condiciones generales hacen que sean sitios muy visitados y accesibles para el público general. Con respecto a las características de ingreso a estos lugares las calificaciones estuvieron entre bueno y excelente, especialmente lo asociado con información, rotulación, accesibilidad a colaboradores e información. La gran ventaja de estos atractivos es que, por ser áreas recreativas, por lo general son muy amplias y las condiciones incentivan a los visitantes a practicar diferentes actividades y los espacios están destinados para que las personas de diferentes edades lo puedan disfrutar. En el $80 \%$ de lugares visitados hay variedad de atractivos. En seguridad también se tiene que reforzar el personal destinado para tal fin, debido a que en algunos sitios es escaso y la presencia de personas vigilantes es muy 
importante, les da mayor tranquilidad a los visitantes. Con respecto a los servicios de alimentación en estos lugares hay variedad, los visitantes pueden adquirir los alimentos en puestos ambulantes, puestos fijos 0 bien llevar comida y utilizar las áreas para picnic.

El manejo ambiental es uno de los aspectos en que deben mejorar, en el caso de los residuos sólidos hay depósitos para tal fin, pero no así para la separación de estos. Con respecto a la calificación de la flora y fauna un $30 \%$ lo calificó de regular, por lo que es importante tomar acciones en función de ello.

Turismo de aventura. Una de las características del turismo de aventura es que no es inclusivo. Ello se debe a que, en principio, las condiciones son riesgosas, pero se pueden adaptar para algunos segmentos de los visitantes, aunque para poder operar tienen que cumplir con todas las medidas de seguridad. Lo otro es que, según datos de la investigación, no visualiza una política empresarial que dirija actividades inclusivas para personas con alguna discapacidad física. También se constató que no hay letreros específicos para personas que tengan limitaciones visuales. En el tema de rotulación, accesibilidad de colaboradores, información, las calificaciones van de excelente a bueno. Estas empresas ya tienen muchos años de estar en el mercado, por lo tanto, tienen vasta experiencia por lo que cuidan mucho los aspectos de calidad y seguridad, principalmente.

Los lugares se caracterizan por ser amplios, donde en un solo sitio se pueden practicar varias actividades a la vez. En muchos casos los visitantes llegan para practicar una actividad, sin embargo, se motiva a practicar otras. La ventaja es que hay varios atractivos en estos lugares. En el tema de seguridad, estos cuentan con el personal adecuado y los dispositivos necesarios, tanto para la seguridad de cada una de las actividades como para la seguridad civil. La mayoría de estos lugares tienen un establecimiento para el consumo de alimentos, los cuales se encuentran en buenas condiciones. El $58.1 \%$ de las personas entrevistadas lo califico como bueno y un $28.6 \%$ excelente. Tanto el servicio al cliente como las condiciones físicas del lugar, obtuvo la calificación de buena a excelente. Ambos elementos han sido fundamentales para que estas empresas sean competitivas en el mercado. Sin embargo, les hace falta trabajar un poco más es en sector ambiental, que de alguna forma lo hacen, pero se requiere de un poco más de rotulación al respecto para sensibilizar a los usuarios de los servicios. 
En el área de la cultura sí se requiere que realicen acciones concretas, debido a que esta no se fomenta en ninguna de las empresas. Esta se puede promover a través de información, de la gastronomía y de actividades complementarias. Finalmente, con respecto a los precios de los sitios de aventura dependen de los tours o actividades que se realicen. Según los sitios estudiados, los precios oscilan entre los $\$ 5000$ a los $\zeta 53000$ (\$USD 8 - 85) e indican precios diferenciados para niños.

Los sitios de educación natural y cultural, estos lugares tienen características muy diversas, pero el común denominador es el tema educativo y varios de ellos se dedican a la investigación, además son lugares aptos para todo público. En la mayoría de los sitios lo que se puede hacer son recorridos educativos, tanto para aprender de la naturaleza como de la cultura general. Estos sitios tienen una gran trayectoria en el tema de educación e investigación, por lo que sus servicios se dirigen a diferentes públicos, entre ellos escuelas, colegios, científicos y turismo en general.

Tanto en el tema de rotulación, información, condiciones generales de acceso e higiene, se considera que están "bien", las calificaciones son entre buenas y excelentes. Con respecto a la parte física de las instalaciones de estos sitios se encuentran en buenas condiciones; parte importante de cada uno de estos lugares son áreas verdes, las cuales se encuentran bien demarcadas con respecto a las aceras, senderos, etc. En el caso de las áreas que están bajo techo, las condiciones físicas están en buenas condiciones, los espacios son amplios, tienen diferentes ambientes, son aptos para desarrollar actividades grupales y se encuentran bien rotulados y señalizados. En estos lugares se puede observar gran variedad de flora, lo que los hace muy atractivos.

Al igual que otros lugares que se han analizado, la debilidad de estos lugares recae en las condiciones de accesibilidad para personas con alguna discapacidad. Ello se puede constatar en las siguientes figuras, donde se evidencia la carencia de rotulación para personas con problemas visuales y que es poca la existencia de barreras de apoyo para facilitarle a las personas el desplazamiento de un lado a otro.

Otro de los aspectos que hay que trabajar es que el $86 \%$ de los lugares visitados no cuenta con letreros que advierta sobre las condiciones riesgosas y tampoco información para prevenir robos o extravíos de objetos. 
Por las características de los lugares, el fomento de la vida silvestre y el uso de abonos orgánicos, las condiciones en estos aspectos evaluados son muy buenas.

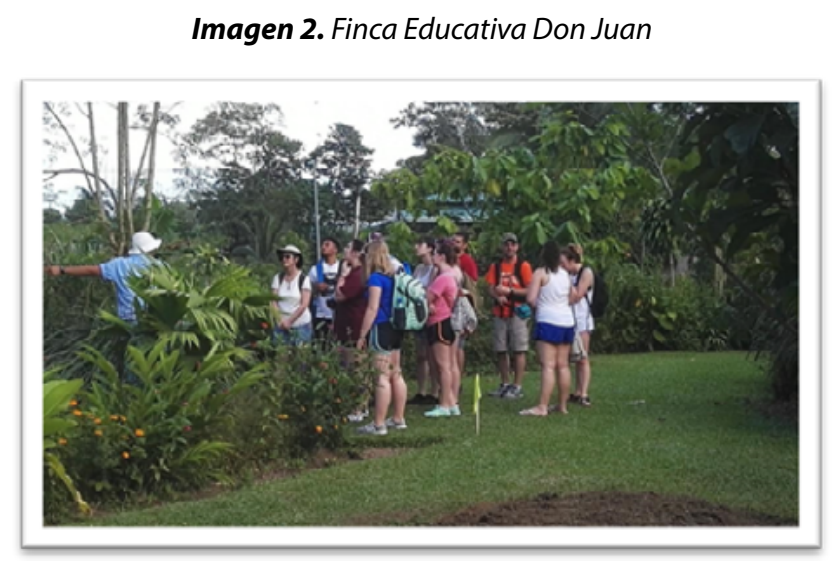

Fuente: Fotografía de Yorlenny Fontana (2017).

En los lugares de rescate de animales silvestres, en términos de seguridad los sitios reúnen las condiciones; sin embargo, es necesario que trabajen en rotulación e información para el visitante en este tema. Los sitios visitados de rescate de animales silvestres, tienen características comunes, debido a que su objetivo es salvaguardar las condiciones de salud de los animales y sensibilizar a los visitantes sobre la importancia de la protección y conservación animal. En el ámbito turístico, estos sitios tienen un sentido más educativo. La planta física de estos lugares se presta para hacer recorridos cortos, no se propicia el desarrollo de actividades grupales ni familiares, porque en realidad no es su propósito. Los visitantes prácticamente son solo espectadores, los cuales están atentos a la observación de los aspectos que se encuentran en exhibición, por lo que no se cuenta con programas de actividades donde se involucre al visitante. La infraestructura de los sitios es de tamaño mediano, por lo que los recorridos se hacen con grupos pequeños de personas. Al igual que los otros sitios analizados en el tema de accesibilidad e inclusión a todas las personas, no cumple con las condiciones para hacerlo, porque no se dan actividades específicas para personas con alguna discapacidad, ni tampoco se cuenta con letreros para personas que tenga problemas de visión. En términos de seguridad los sitios reúnen las condiciones; sin embargo, es necesario que trabajen en rotulación e información para el visitante en este tema. En aspectos de protección ambiental los lugares se encuentran bien, se identificaron acciones en función del fomento de la vida silvestre en el jardín y prácticas de protección de la flora y fauna. 


\section{CONCLUSIONES Y RECOMENDACIONES}

El turismo supone acceso a gran cantidad de personas, quienes en principio deben tener el derecho al ocio, por lo tanto, es una actividad que disfrutan los diferentes estratos sociales. Sin embargo, la accesibilidad a los diferentes sitios se da en función de una marcada diferencia del poder adquisitivo de las personas. Claro está que, en Costa Rica, la visitación del turismo nacional correspondiente a los estratos sociales de menor nivel económico se da a sitios públicos o lugares de menor costo. Con lo anterior se relaciona el turismo social, el cual tiene como característica los servicios de gastos reducidos, el uso de transporte público, entre otros.

La sostenibilidad, es un tema que está intrínseco en la actividad turística. La implementación de acciones en función de la sostenibilidad se visualiza más claramente en el sector privado, ya que ello implica un tema de competitividad en el mercado. Aunque en la actividad turística están involucrados tanto el sector público como privado, el sector público requiere hacer acciones que respondan a políticas públicas asociadas con la sostenibilidad. Para ello, se requiere que se haga una adecuada gestión y ejecución de recursos.

El ocio es una actividad que le permite al ser humano distraerse y ubicarse mental y físicamente en un contexto diferente, donde puede desarrollar la mente y adquiir mayores conocimientos. El ocio se refiere al uso del tiempo libre de diversas formas, por lo que no necesariamente va a implicar un costo. Ello se refiere a que tiene una orientación más marcada en la experimentación de vivencias. Su relación con el turismo es que también implica descanso en días libres, pero en ésta prevalece el pago de servicios.

Los sitios visitados en la investigación están ubicados en diferentes lugares de Costa Rica, cuyas características territoriales son diversas, donde se encuentran atractivos naturales, atractivos con intención y sin intención, eventos y contextos culturales. La diversidad de los atractivos fortalece la oferta turística, en algunos de los casos su desarrollo ha sido de manera espontánea inicialmente $y$, en otros, de forma planificada, tanto desde el seno de la unidad productiva, como en el destino turístico.

Las diez categorías de análisis reflejan la riqueza turística que posee el país, con una clara orientación de productos y servicios que se complementan entre sí, considerando la aventura, la naturaleza, la historia, el patrimonio, la cultura, entre otros. Esto es el resultado de un claro aprovechamiento de los recursos con que se cuenta y una visión de desarrollo que ha beneficiado a gran parte de la población nacional, tanto en sitios rurales como urbanos. Sin embargo, en el sector turístico 
también existen contradicciones y asimetrías que ponen en tela de juicio el vínculo entre esta actividad y el desarrollo humano sostenible en ámbitos locales, que ameritan ser investigadas posteriormente.

Las tendencias del ocio y el turismo se orientan hacia la sostenibilidad, enmarcado en los aspectos económicos, sociales y ambientales, en lo cual se viene trabajando hace algunos años; pero en la actualidad se continúan con mayores esfuerzos fortaleciendo la oferta turística. Un aspecto que es importante de rescatar, es la contribución de esta actividad al desarrollo humano, lo que en algunos casos ha fomentado crecimiento económico y cambios en los estilos de vida. Estas también son dimensiones susceptibles de ser investigadas desde visiones críticas e integradoras.

Es fundamental que el turismo se desarrolle con una adecuada gestión, especialmente en lo que se refiere a la planificación de los destinos turísticos, considerando principalmente la capacidad de carga de los sitios más sensibles a la visitación, cuyo impacto negativo tanto en aspectos sociales como ambientales, se pude mermar de manera oportuna.

Los turistas actualmente lo que buscan son experiencias, en ese sentido es necesario que los servicios estén acompañados de una gran cantidad de valores agregados que las fundamenten.

El uso de las nuevas tecnologías es una de las grandes tendencias ya que han facilitado de manera oportuna la operación comercial de las empresas turísticas, especialmente por la reducción de costos, la agilidad en la respuesta y que se acortan distancias. La tecnología viene a complementar los servicios en los cuales siempre prevalece la personalización, el contacto entre las personas implica un gran valor en el servicio.

Los lugares visitados, en términos generales cuentan con las condiciones para la visitación de turistas; sin embargo, requieren algunas mejoras especialmente en el tema de accesibilidad. A continuación, algunas recomendaciones al respecto por cada categoría de análisis: 
1. Los sitios históricos - patrimoniales contemplados en la investigación poseen una serie de aspectos positivos, entre ellos la riqueza histórica. Sin embargo, requieren de algunas mejoras. Por ejemplo, en rotulación, deben de mejorar sustancialmente la accesibilidad para personas con alguna condición especial. Situación similar tiene los lugares acuáticos ya que no existen las condiciones adecuadas para el traslado de personas con alguna discapacidad, faltan barras de apoyo, demarcación de aceras y rotulación al respecto. También deben hacer mejoras sustanciales en implementar prácticas ambientales.

2. Las actividades culturales programadas son visitadas mayoritariamente por los costarricenses; sin embargo, por su contenido cultural son actividades que se deben promocionar para que sean visitadas por los turistas extranjeros, ya que en estos espacios se refleja gran parte de las identidades en Costa Rica. Es por ello que se hace necesario que el ente rector destine recursos promocionales y de apoyo a estas actividades.

3. Los sitios de atracción cultural son lugares que carece de políticas visibles de manejo ambiental, por lo que deben hacer esfuerzos fuertes en este sentido. En lo que sí se encuentran en muy buenas condiciones es en los aspectos culturales, al ser el elemento principal del producto turístico que ofrece.

4. Los sitios de atracción natural deben de mejorar en rotulación, en aspectos de seguridad, especialmente para que se anuncie sobre las condiciones riesgosas de los sitios, con un sentido más de prevención.

5. Las empresas e instancias que ofrecen servicios turísticos con actividades de entretenimiento han hecho esfuerzos en el cumplimiento de la Ley $\mathbf{7 6 0 0}$ (Ley de igualdad de oportunidades para las personas con discapacidad). Sin embargo, aún falta mucho trabajo qué hacer para que la actividad turística sea realmente inclusiva. Se carece de barreras de apoyo para que las personas con alguna discapacidad puedan movilizarse con mayor facilidad y; otra gran debilidad que se detectó, es que las empresas tampoco hacen esfuerzos en propiciar actividades recreativas adaptadas a personas con alguna discapacidad. 
6. Los lugares de recreación y esparcimiento: el problema que prevalece en estos sitios es la condición de seguridad, ya que en algunos de los lugares no hay información para prevenir robos y extravíos. De igual manera la demarcación de las aceras y otros espacios no está claramente delimitados. Por lo que hay que hacer grandes esfuerzos en este sentido.

7. Una de las características del turismo de aventura es que no es tan inclusivo. Ello se debe a que, en principio, las condiciones son riesgosas, pero se pueden adaptar para segmentos amplios de personas, aunque para poder operar tienen que cumplir con todas las medidas de seguridad. Otro aspecto es que no se visualiza una política empresarial que dirija actividades exclusivas para personas con alguna discapacidad física. También se constató que no hay letreros específicos para personas que tengan limitaciones visuales. Es necesario que este tipo de empresas diseñe algunas actividades complementarias a las tradicionales para hacer partícipe del lugar a personas con alguna discapacidad especial.

8. Los sitios de educación natural y cultural: al igual que otros lugares que se han analizado, la debilidad recae en las condiciones de accesibilidad para personas con alguna discapacidad. Hay carencia de rotulación para personas con problemas visuales y es poca la existencia de barreras de apoyo para facilitar a las personas el desplazamiento de un lado a otro. Estos lugares son aptos para todo público, por lo cual es indispensable que adapte las condiciones físicas de manera que permita con mayor facilidad el traslado y recorridos a personas con alguna discapacidad especial.

9. En los lugares de rescate de animales silvestres, en términos de seguridad, los sitios reúnen las condiciones; sin embargo, es necesario que trabajen en rotulación e información para el visitante en este tema.

Todo lo anterior refleja la necesidad de trabajar más fuertemente el tema de inclusividad. Si bien es cierto, se han hecho esfuerzos, la variable de inclusividad aún está ausente en algunos de los sitios estudiados. Por ello se requiere mayor compromiso de parte de los empresarios turísticos y mayor fiscalización por parte del Instituto Costarricense de Turismo (ICT). 
Sin duda alguna, se requiere de políticas públicas que propicien más rigurosidad en el cumplimiento del derecho universal al ocio, la recreación y el turismo. Este tema está altamente vinculado con el turismo social. Por ello, su promoción requiere que se contemplen aspectos de accesibilidad, más allá de la Ley 7600.

A pesar de que el ocio es considerado como un derecho humano para el descanso y el esparcimiento, parte de la población es excluida del acceso a algunos servicios y destinos turísticos debido a factores socioeconómicos. Esta situación se puede intensificar por la situación económica que enfrenta el país desde la crisis de 2008 hasta la crisis sanitaria generada por el COVID-19 durante 2020 y 2021 . A pesar de ello, el ICT podría hacer mayores esfuerzos en incentivar la visitación a estos lugares haciendo un trabajo conjunto con los empresarios, de manera que en los lugares donde se cobra el ingreso, se establezcan precios más accesibles.

No se puede negar que la población costarricense de alguna manera tiene acceso a diferentes sitios de atracción turística. Sin embargo, aún no existen las condiciones apropiadas que le permita acceder de manera universal, sin segregaciones de ninguna índole, ejerciéndose así el derecho al ocio, a la recreación y al turismo.

Entre las principales líneas de trabajo que conduzcan al cumplimiento del derecho universal al ocio y el turismo, se plantean las siguientes:

- Las autoridades públicas y las empresas privadas deben fomentar el desarrollo del turismo social y asociativo, de manera que permita que esta actividad sea más accesible para la mayoría de la población.

- Se deben hacer esfuerzos con la elaboración de políticas públicas y acciones concretas para que la población mejore su nivel de vida y pueda acceder al ocio y al turismo.

- Los gobiernos locales deben de fomentar más el ocio y el turismo facilitando aspectos de seguridad y condiciones físicas de los lugares públicos donde se pueden practicar diversas actividades.

- Se deben establecer lineamientos y compromisos por parte de las empresas de turismo, para que los servicios sean más accesibles en aspectos físicos y económicos, y se incremente el turismo nacional. 
- Debehaber mayorfiscalización de las autoridades competentes en el cumplimiento de la legislación con respecto al manejo integral de los residuos sólidos en lugares públicos.

- Se requiere de articulación de esfuerzos entre el sector público y privado para que la actividad sea más inclusiva y accesible a la población en general.

- Fomentar la investigación, la formación e incentivos para que el ocio y el turismo sean más accesibles y favorezcan la equidad, la justicia social y ambiental desde enfoques de género, etnia, clase, etc.

- Implementar buenas prácticas en el sector privado, como aplicar la legislación en aspectos ambientales, sociales y culturales; no discriminar clientes y adecuar las infraestructuras a un público general.

- Implementar buenas prácticas por parte del sector público en: como cumplir las leyes, fomentar proyectos de desarrollo, incluir la accesibilidad en todo su accionar, implementar políticas que favorezcan la sector privado, generar un marco normativo que se adecúe a las condiciones actuales del sector turismo.

- Otros aspectos que también le corresponde al sector público en alianzas con sectores privados es: considerar la accesibilidad como un eje trasversal en las políticas, aplicar principios de accesibilidad en todos los ámbitos (infraestructura, tecnología, transporte, entre otros). También, fomentar el acceso al empleo, la cultura, el ocio, etc.

- Promover la solidaridad social y la participación ciudadana por un turismo abierto para que se accesible a la mayoría de la población.

- Fomentar campañas de promoción turística para el mercado nacional con precios más atractivos y razonables.

- Incluir en los planes, programas y proyectos aspectos que fomenten la participación y la inclusión de captación de turistas que no hayan accedido tradicionalmente a estos servicios. 


\section{BIBLIOGRAFÍA}

Águila Soto, C. (2007). Sobre el Ocio y la posmodernidad. Wanceulen Editorial Deportiva. S. L. Sevilla, España. ISBN: 978-84-9823-206-6

Alburquerque, F. (2001). La importancia del Desarrollo Económico Local. Argentina: A. Vásquez Barquero y O. Madoery. Eds.

Almirón, A., Bertoncello, R. y Troncoso, C. A. (2006): "Turismo, patrimonio y territorio: Una discusión de sus relaciones a partir de casos de Argentina", Estudios y perspectivas en turismo, 15:101-124.

Boisier, S. (2005). ¿Hay espacio para el desarrollo local en la globalización? Revista de la CEPAL 86, agosto. Obtenido de: https://repositorio.cepal. org/bitstream/handle/11362/11068/1/086047062_es.pdf

Bigne, E., Font, X. y Andreu, L. (2000) Marketing de destinos turísticos. ESIC Editorial. Madrid España: ISBN: 9788473562621

Catholic. Net (2018). La leyenda de Juana Pereira y Nuestra Señora de los Ángeles. es.catholic.net. Recuperado de: http://es.catholic.net/op/articulos/53598/cat/1 16/la-leyenda-de-juana-pereira-y-nuestra-senorade-los-ngeles.html\#modal

Centro de Investigación y Conservación del Patrimonio-MCJ (S.F.) Patrimonio Histórico Arquitectónico. Centro de Conservación de Patrimonio Cultural. Recuperado de: http://www.patrimonio.go.cr/patrimonio/index.aspx

Chang, G. (2016). Acervo Turístico Cultural Costarricense. San José, C.R.: EUNED, 2016.

Cuenca, M. (2004). Pedagogía del Ocio. Modelos y propuestas. Ed. Universidad de Deusto. España 
Cuenca, M. (2000). Ocio humanista: Dimensiones y manifestaciones actuales del ocio. Universidad de Deusto. Bilbao, España. Recuperado de: http:// www.deusto-publicaciones.es/deusto/pdfs/ocio/ocio16.pdf

Csikszentmihalyi, M. (2001) Ocio y creatividad en el desarrollo humano. Ocio y Desarrollo Humano: potencialidades del ocio para el desarrollo humano. Universidad de Deusto. Bilbao, España. Recuperado de: http://www. deusto-publicaciones.es/ud/openaccess/ocio/pdfs_ocio/ocio18.pdf

Fernández, A. y Villarán, A, (2017). Promoción y comercialización de productos y servicios turísticos locales. Ediciones Paraninfo, S.A. ISBN-10: 8428339929

Fletcher, J., Fyall, A., Gilbert, D., y Wanhill, S. (2007) Tourism: Principles and Practice. Harlow, United Kingdom: Pearson. ISBN 9781292172361

Gándara, José. (2004). La Calidad y la Competitividad de los Destinos Turísticos Urbanos. Turismo - Visão e Ação. Vol. 6, n. 1. Jan - abril. DOI:10.14210/ rtva. v6n1.p69.

Gascón, J. (2016). Deconstruyendo el derecho al turismo. Revista CIDOB d'Afers Internacionals. Obtenido el 12 de noviembre del 2020, de http:// www.coodtur.org/wp-content/uploads/2016/09/Deconstruyendo_el_ derecho_al_turismo_Re.pdf

ICT (1997). Concepto de Sostenibilidad Turística. Instituto Costarricense de Turismo. Obtenido el 12 de noviembre del 2020, de https://www.ict. go.cr/es/sostenibilidad/cst.html 
Iso-Ahola, S. (1980) Social Psychology of Leisure and Recreation. C. Brown Company Publishers, E.U.A.

Kelly, J.R. y Godbey, G. (1992). The sociology of leisure. State College. PA: Venture Publishing, Inc.

Lázaro. Y. (2006) Derecho al Ocio. En Aproximación Multidisciplinar a los estudios de Ocio. Documentos de Estudios de Ocio, n 31. Bilbao. Universidad de Deusto.

McCabe, S. y Diekmann, A. (2015). The rights to tourism: Reflections on social tourism and human rights. Tourism Recreation Research 40(2):1-11. DOI: 10.1080/02508281.2015.1049022

Muñiz, A., (2001). La política del Turismo Social. Obtenido el 12 de noviembre del 2020 de www.entornoturistico.com/wp-content/uploads/2018/04/ La-Politica-del-Turismo-Social.pdf

Neulinger, J. (1974). The Psychology of Leisure. Research Approaches to the study of leisure. Thomas Publisher, Springfield, Illinois, U.S.A.

Noyola, L. Y. y Campón, A. M. (2016). La percepción de la autenticidad del destino cultural y su relación con la satisfacción y lealtad. ROTUR, Revista de Ocio y Turismo, 11: 65-76. ISSN: 1888-6884.

OMT (1999). Código Ético Mundial para el turismo. Organización Mundial del Turismo. Obtenido el 12 de noviembre del 2020, de http://agronegocios. catie.ac.cr/images/pdf/Codigo_Etico_Mundial_para_el_Turismo.pdf 
OMT (2008). Entender el turismo: Glosario básico. A partir de las recomendaciones internacionales para estadísticas de turismo RIET. Organización Mundial del Turismo. Recuperado de: https://webunwto.s3-eu-west-1. amazonaws.com/2019-08/glossary_ES.pdf

OMT (2018). ¿Por qué el turismo? Organización Mundial del Turismo. Obtenido Recuperado de http://www2.unwto.org/es/content/por-que-el-turismo

ONU (1948). Declaración Universal de Derechos Humanos. Organización de las Naciones Unidas. Recuperado de: http://portal.unesco.org/es/ ev.php-URL_ID=26053\&URL_DO=DO_TOPIC\&URL_SECTION=201. html

ONU (s.f.) ¿Qué son los derechos humanos? Organización de las Naciones Unidas. Obtenido el 12 de noviembre del 2020, de https://www.un.org/es/ sections/issues-depth/human-rights/index.html

Osorio, M., Ramírez de la O, I. L. y Viesca, C. (2016). Tendencias del turismo hasta 2030. Contrastes entre lo internacional y lo nacional. En: Nel-lo Andreu, Marta Gemma i Font Barnet, Alba (eds.), Anudar red. Temas pendientes y nuevas oportunidades de cooperación en turismo, URV, Tarragona, 2016, p. 107-127. DOI: 10.17345/9788484244905. Universidad Autónoma del Estado de México. Recuperado de: http://ri.uaemex.mx/ bitstream/handle/20.500.11799/68788/Cap_Tendencias_COODTUR. pdf? sequence $=3$

Puertas, X. (2007). Gestión del ocio en ámbito turístico. Madrid. Editorial Síntesis.

Puertas, X. (2008). Modelo de escaneo. Recuperada de: http://worldleisure. org/wp-content/uploads/2016/05/2008_WLC_Quebec_-Book-of-abstracts.pdf 
Quesada. R. (2014) Elementos de Turismo. 2da edición. San José Costa Rica: EUNED. ISBN 978-9968-31-817-4

Rodríguez Antón, J. M. y Alonso Ma. Mar. (2009). Nuevas Tendencias y Retos en el Sector Turismo: un Enfoque Multidisciplinar. Delta Publicaciones, Madrid. Recuperado de: http://www.encuentros-multidisciplinares.org/Revistan\%C2\%BA32/BIBLIOGRAF\%C3\%8DA_MULTIDISCIPLINAR.pdf

Socatelli, M. (2015) Mercadeo aplicado al Turismo: La comercialización de Servicios, productos y destinos turísticos Sostenibles. San José Costa Rica: EUNED. ISBN: 978-9968-48-102-1.

Stebbins, R. (2004). Serious leisure, volunteerism and quality of life. In J. T. Haworth \& A. J. Veal (Eds.), Work and leisure (pp. 200-212). Routledge.

Swarbrooke, J. (1998). Sustainable Tourism management. CAB International Publishing. Oxford, UK.

Vilar, L. G., y Vidal, G. G. (2010), Fundamentos teóricos para una gestión turística del patrimonio cultural desde la perspectiva de la autenticidad, Eumed.

WTM (2017). World Travel Market Industry Report 2017. Recuperado de: http:// london.wtm.com/RXUK/RXUK_WTMLondon/2017/WTM_Reports/ WTM_2017_Industry_Report.pdf?v=636456423149143122. 